\title{
LA EVOLUCION DE LOS MOVIMIENTOS URBANOS POPULARES EN MEXICO ENTRE 1968 Y 1988 (*)
}

\author{
Vivienne Bennett (**)
}

\section{INTRODUCCION}

En las tres décadas que van de 1940 a 1970, México experimentó un alto crecimiento económico sostenido, ya que la política del gobierno estaba enfocada a incentivar la economía y crear la infraestructura necesaria para una industrialización diversificada y una agricultura comercial. Durante este período, más conocido como el «milagro mexicano», las ciudades de México crecieron a un ritmo inesperado y sin precedentes. Sin embargo, las condiciones de vida de las zonas urbanas se iban degradando, ya que el gobierno no consiguió extender los servicios públicos a los núcleos de población que formaban el cinturón de las grandes ciudades (muchos de los cuales eran asentamientos irregulares). Las oportunidades de trabajo que podían ofrecer las ciudades no eran acordes con la gran cantidad de emigrantes del medio urbano al medio rural o con la cantidad cada vez más creciente de bachilleres o licenciados universitarios en busca de empleo en su especialidad.

En 1968 el descontento del medio urbano terminó por explotar cuando los estudiantes, apoyados por parte de la clase popular urbana, armaron protestas contra la represión del gobierno, la falta de trabajo y las pésimas condiciones de vida. Las protestas de 1968 finalizaron con una represión violenta por parte de tropas gubernamentales que dispararon contra una manifestación pacífica en la Ciudad de México, matando aproximadamente a 200 personas (1).

Durante los veinte años que transcurren entre 1968 y 1988 se hicieron patentes en la economía de México las distorsiones de su modelo de desarrollo, y éstas coincidieron con conflictos internos del sistema político. La apertura democrática del presidente Echeverría a principios de los 70 dió paso a la ley de reforma electoral del presidente López Portillo de 1977, en la que se legalizaron los partidos políticos de la oposición.

Ya por 1986, el partido en el poder, el Partido Revolucionario Institucional o PRI, era tan rígido y poco democrático en su organización interna que se formó dentro del

$\left(^{*}\right)$ Una parte de este documento apareció ya en un capitulo de la misma autora, "The Evolution of Urban Popular Movements in Mexico Between 1968 and 1988»). En Escoba, Arturo, y Sonia Alvarez (coordinadores), The Making of Social Movements in Latin America: Identity, Strategy and Democracy. Boulder: Westview Press, 1992. Lawrence Herzog, Sonia Alvarez, Arturo Escobar, Jeff Rubin, Judy Adler Hellman y Maria Lorena Cook aportaron su ayuda con comentarios sobre los borradores previos a este documento. Roderick Michener proporcionó ayuda valiosa con la recopilación de datos. Soy únicamente responsable de la presentación e interpretación de los datos contenidos en este documento.

(**) Vivienne Bennet está en el Departamento de Ciencias Políticas del Sarah Lawrence College, Bronxvill ; Nueva York,

(1) Stevens, Evelyn P. Protest and Response in Mexico. Cambridge, Mass.: The MIT Press, 1974, p.237. mismo partido una "corriente democrática» que instaba a llevar a cabo las reformas democráticas necesarias. Las llamadas a las reformas democráticas de dicha corriente produjeron una escisión dentro del PRI entre grupos que apoyaban la continuación de la política mexicana a la «vieja usanza» y los que apoyaban la liberalización. Estas divergencias llegaron a su punto álgido cuando en 1987 la «Corriente Democrática» se escindió del PRI formando un partido nuevo, el Frente Democrático Nacional (FDN) y nombró a su propio candidato, Cuauhtémoc Cárdenas, para las elecciones presidenciales de 1988.

En dicho año el PRI obtuvo la presidencia del gobierno con el $50,7 \%$ de los votos emitidos, es decir, con la menor cantidad de votos obtenida hasta entonces en una elección presidencial. El escrutinio mostró que el PRI había sufrido una pérdida espectacular de votos del medio urbano en la mayor parte del país y que su derrota fue sonada frente a Cárdenas en la misma Ciudad de México.

¿Qué ocurrió en México durante las dos décadas marcadas por la represión del movimiento estudiantil en 1968 y la casi victoria del candidato a la presidencia de la oposición, Cuauhtémoc Cárdenas, en 1988? ¿Cómo pudo evolucionar la oposición mexicana desde la tremenda represión sufrida en 1968 hasta la victoria parcial en las urnas de las elecciones presidenciales de 1988? Los votos emitidos en 1988 mostraron un cambio significativo en el comportamiento político de los indigentes, pero se trataba de un cambio que no sólo estaba relacionado con la política electoral, sino también con los extendidos movimientos populares que tradicionalmente habían rechazado los procesos electorales.

Los resultados de las elecciones presidenciales de 1988 constituyen un cambio evidente en las relaciones entre la sociedad civil y el sistema político en México. Los observadores actuales de México coinciden en señalar que el alejamiento del voto urbano del PRI se debe al incremento del descontento en las ciudades y de los movimientos populares desde 1982 y más particularmente desde el terremoto de 1985. De hecho, los movimientos urbanos populares en México no empezaron en los años precedentes a las elecciones de 1988, sino que por aquella época ya estaban bastante consolidados en muchas ciudades mexicanas.

Los movimientos populares de los 70 , provocados por la falta de vivienda y servicios públicos, ya tenían precedentes en los años 50 y 60 , pero se multiplicaron rápidamente después de 1968, el año que se viene conociendo normalmente como el año de la ruptura entre el pasado y el presente en 
términos de respuesta popular contra la debilidad del modelo de desarrollo de México.

Los movimientos urbanos populares se produjeron en tres oleadas principales; la primera fue a principios de los 70 , la segunda desde 1979 hasta 1983 y la tercera entre 1985 y 1988. Este documento analiza en detalle las primeras dos oleadas y ofrece una visión general de la tercera oleada, sugiriendo que los movimientos urbanos populares han tenido un efecto transformador en el sistema político y social de México.

\section{LA PRIMERA OLEADA DE MOVIMIENTOS URBANOS POPULARES - PRINCIPIOS DE LOS 70}

La primera oleada de movimientos urbanos populares (MUP) de México tuvo lugar a principios de los 70 como respuesta a las faltas generales de la vida urbana: falta de trabajos, falta de movilidad, servicios urbanos inadecuados, escasez de viviendas y la indiferencia del gobierno y su incapacidad o la violencia relacionada con estos problemas (2). Estos MUP surgieron en los estados norteños de Chihuahua, Nuevo León y Durango y en el estado sureño de Oaxaca.

En 1970 y 1971 un grupo de estudiantes de la Ciudad de México que habían adoptado la ideología maoísta y que creían que una revolución socialista sólo podría ocurrir si empezaba fuera de la capital, decidieron que era hora de dejar la ciudad y desplazarse a las provincias para trabajar con los campesinos y los pobres urbanos. Tuvieron su mayor impacto en Durango y Monterrey. En Durango comenzaron liderando una lucha que terminó con éxito con una bajada en las tarifas de agua. A finales de 1972 los vecinos que ganaron la batalla contra las altas tarifas del agua se unieron en un nuevo objetivo: la adquisición de tierra. Después de nueve meses el grupo llegó a un acuerdo con la agencia de la vivienda del gobierno federal, el INDECO, que accedió a proporcionarles 20 hectáreas de tierra a muy bajo costo. La creación en 1973 de la Colonia División del Norte en esa tierra permitió la consolidación del grupo, la organización de otras invasiones de tierra que también tuvieron éxito, el apoyo de varias luchas de campesinos y obreros y la formación en 1979 del Comité de Defensa Popular (CDP-Durango) (3).

En Chihuahua, la matanza de cinco guerrillas urbanas durante asaltos a tres bancos en 1972 sirvió como catalizador para la formación del Comité de Defensa Popular CDPChihahua. La colonia Francisco Villa, una colonia paracaidista, organizó protestas contra la represión del gobierno que recibieron un importante apoyo popular y condujeron al establecimiento del CDP, una coalición compuesta por la Colonia Francisco Villa, siete organizaciones obreras independientes y una organización de estudiantes (4).

(2) El término «movimiento urbano popular» comprende una amplia gama de organizaciones. Los MUP pueden consistir en un solo movimiento, una confederación de varios movimientos, un grupo levemente aliado de colonias populares, o incluso una sola colonia popular. La mayoría de los MUP a los que se hace referencia en este capitulo entran en las primeras tres categorías.

(3) Cruz, Marcos, Gonzálo Yáñez, Elio Villaseñor y Julio Moguel (eds.) Llegó la hora de ser gobierno: Durango, Testimonios de la lucha del Comité de Defensa Popular General Francisco Villa. México D.F.: Equipo Pueblo, 1986

(4) Orozco, Victor. «Las luchas populares en Chihuahua). Cuadernos Políticos. núm. 9, 1976, pp.49-66
En Monterrey, las invasiones de tierras empezaron a producirse con regularidad en 1971 conforme la población de la ciudad se enfrentaba a una situación de escasez de viviendas insostenible debido a los fuertes flujos migratorios hacia la ciudad en los años 50 y 60 . Algunas de las invasiones fueron llevadas a cabo por estudiantes activistas que pertenecían a la misma organización maoísta clandestina que los estudiantes de Durango. Mientras que muchas de las invasiones de tierra de Monterrey se encontraron con la represión del Estado, la mayoría logró sus objetivos de establecerse, básicamente porque el Estado no pudo ofrecer otra alternativa de vivienda (5). Muchos de los nuevos asentamientos irregulares ocupados ilegalmente estaban muy bien organizados y contaban con líderes altamente politizados que buscaban colocar la apropiación de la tierra dentro de un contexto mayor de lucha de clases. Una colonia en particular, la Colonia Tierra y Libertad, estaba organizada por estudiantes militantes que enfrentaron las necesidades básicas de vivienda, electricidad, agua, colegios, etcétera, mediante un enfoque maoísta de organización colectiva, es decir, estableciendo líderes de manzanas, asambleas generales, y domingos de trabajo comunitario. La capacidad de la colonia para construir una organización interna y a la vez apoyar otras invasiones de tierra, luchas por los alquileres, y huelgas de trabajadores tuvo como consecuencia la formación en 1976 del Frente Popular Tierra y Libertad (FPTyL). El Frente estaba dirigido desde la Colonia Tierra y Libertad por los líderes estudiantiles de la invasión original.

El FPTyL estaba compuesto inicialmente por 31 colonias populares, 16 grupos de inquilinos, 3 asociaciones ejidales y varios grupos de trabajadores (incluidos conductores de autobús, vendedores ambulantes y fotógrafos callejeros) (6) que llegaron a agrupar entre 50.000 y 350.000 personas (según las distintas fuentes) (7).

En Oaxaca, el movimiento urbano popular estaba centrado en la ciudad de Juchitán. Una vez más fueron los estudiantes los que asumieron el liderazgo creando en 1973 la Coalición de Obreros, Campesinos y Estudiantes del Istmo (COCEI) (8). La COCEI se sirvió de huelgas, marchas, ocupaciones de edificios públicos y negociaciones para presionar al gobierno a que mejorara las condiciones de vida y de trabajo. Esta organización se ganó rápidamente el apoyo de amplios sectores de la población campesina y entre los residentes de la ciudad con bajos ingresos porque trabajaba de parte de ambos grupos. En el sector de la agricultura, la

(5) El primer programa de viviendas sociales subvencionadas por el gobierno estatal no se puso en marcha hasta mediados de los años 70 .

(6) Pérez Güemes, Efrain y Alma Rosa Garza del Toro. «El movimiento de posesionarios en Monterrey, 1970-1983». Seminarios sobre movimientos sociales en México, Región Noreste, Monterrey, Nuevo León, México, 1984, p.42.

(7) En 1982, un documento del gobierno (Castañeda, Victor. «La acción del Estado frente a las demandas de suelo y vivienda de los sectores populares en Monterrey.» Estudios Políticos, núm. 4/5, 1985-86, pp. 77-78) declaró que había aproximadamente 34.000 familias viviendo en 190 asentamientos irregulares en Monterrey. Por tanto habría una media de 179 familias por asentamiento -lo cual es una media demasiado baja- . De las 34.000 familias, el documento asignó el $25 \%$ ( 8.500 familias o 51.000 personas) al FPTyL. Por el otro lado, Pérez Gëmes y Garza del Toto (op. cit., Apéndice) citan el número de afiliados al FPTyL en 350.000 personas, para una media de 11.290 personas por colonia (o 1.881 familias) - lo cual es una cifra demasiado alta-. Por tanto, el verdadero número de afiliados al FPTyL ha de estar entre 50.000 y 350.000 .

(8) Rubin, Jeffrey W. "Political Mobilization and the Myth of State Corporatism». En Popular Movements and Political Change in Mexico, editado por Joe Foweraker y Ann Craig. Boulder: Lynne Rienner, 1990 
COCEI luchó con éxito para la aplicación de límites en la posesión de tierra, para la distribución de tierra entre los campesinos, y contra incrementos en los impuestos; también mejoró el acceso que los campesinos tenían a las estructuras de poder local. En las zonas urbanas, la COCEI apoyó y organizó huelgas que llevaron a mejoras en los salarios y prestaciones, protestó contra los aumentos en los costos del transporte público $\mathrm{y}$, en general, procuró hacer más consecuente a la administración de la ciudad.

De las organizaciones que formaron la primera oleada de movimientos urbanos populares, la COCEI fue la única que participó en las elecciones. Mientras los otros MUP descartaron la participación electoral como reformista y como una forma ineficaz de enfrentarse con las genuinas necesidades del pueblo, la COCEI consideró la participación en las elecciones como una estrategia útil y válida.

Por tanto, además de sus tácticas de organización directa, la COCEI presentó candidatos independientes en las elecciones municipales a principios de los años 70. Dado el control que ejercía el PRI sobre los resultados de las elecciones y el hecho de que hasta 1977, legalmente no existía ningún partido izquierdista, la COCEI no tenía posibilidades de ganar durante los años 70 . No obstante, aprovechó con éxito su participación en las elecciones para extender la organización, y como un podio desde el cual denunciaría el fraude electoral y expondría las prácticas no democráticas del gobierno. A pesar de la represión ejercida por el gobierno y los grupos paramilitares de derecha, la COCEI continuó organizándose con un significante apoyo popular.

¿Qué es lo que destaca en los movimientos de la primera oleada de los MUP en México? Primero, cada uno de estos movimientos consistía en la construcción de nuevos canales para la expresión de las necesidades de los pobres urbanos. Fue un intento explícito de estos movimientos de evitar los canales tradicionales que consideraban incapaces de resolver la creciente crisis urbana. Desde finales de los años 30 , el gobierno mexicano ha pretendido canalizar las necesidades de los ciudadanos - los campesinos, los trabajadores y los sectores populares- a través de las organizaciones de masas del partido dirigente, el PRI (9). El motivo de cada organización de masas consistía en transmitir las necesidades de su sector al gobierno federal, y mediar la respuesta.

A principios de los años 70 , dos de las organizaciones de masas del PRI, la Confederación de Trabajadores Mexicanos (CTM) y la Confederación Nacional de Organizaciones Populares (CNOP), comenzaron a organizar invasiones de tierras en las zonas urbanas. Permitir que la CTM y la CNOP realizaran invasiones de tierra era una de las formas para mantener a los pobres urbanos vinculados al PRI y bajo su control. Sin embargo, ni la CTM ni la CNOP pudieron hacer frente a la demanda de vivienda, y ninguna de las dos representaba verdaderamente al pueblo. Los MUP, por tanto, se disputaban la misma base que las organizaciones oficiales de masas, y su éxito en cuanto al apoyo popular es

(9) En los años 70, las organizaciones de masas consistían en la Confederación de Trabajadores Mexicanos (CTM); la Confederación Nacional Campesina (CNC); y la Confederación Nacional de Organizaciones Populares (CNOP). una indicación de que por supuesto estaban llenando un hueco que el sistema dominante había dejado (10).

La segunda característica digna de destacar de los MUP es el hecho de que respondían mejor ante las necesidades de los ciudadanos. Se creó una nueva relación entre las masas que formaban la base del sector popular y los activistas que eran sus dirigentes. Esto se consiguió al establecer estructuras de organización que permitían la comunicación entre las masas y sus dirigentes - reuniones vecinales, asambleas abiertas, etcétera-. Mientras las estructuras internas de los nuevos MUP han sido algo menos que verdaderamente democráticas, la mayoría de los MUP han logrado las necesidades mínimas de sus bases en cuanto a vivienda y servicios. Los MUP representaban una alternativa a las organizaciones oficiales de masas que los pobres ya habían visto desde hacía mucho tiempo como cooptativas.

Finalmente, el tercer aspecto que destaca sobre la primera oleada de los MUP es su surgimiento - los cuatro surgieron en 1972 (Chihuahua y Durango) o en 1973 (Monterrey y Juchitán)- L La primera oleada responde a dos características de la cultura política en México de la primera mitad de los años 70: a) la existencia de una generación de estudiantes militantes que respondieron a la represión violenta de 1968 y 1971 a través de la búsqueda de vinculaciones directas con las masas, y b) la "apertura democrática» ofrecida por el presidente Echeverría después de 1972. La «apertura democrática» creó nuevos espacios para la organización popular y a la vez mantuvo para el gobierno el privilegio de aplicar cualquiera de sus métodos usuales de control cuando fuera necesario (la cooptación y la represión).

\section{LA REPRESION Y EL REFLUJO DE LOS MOVIMIENTOS URBANOS POPULARES - 1976 A 1978}

Desde 1976 hasta 1978, hubo un reflujo en el desarrollo de los movimientos urbanos populares, principalmente como respuesta a un incremento en la represión (11). Para el año 1976, el presidente Echeverría había abandonado sus pretensiones hacia la reforma social a la vista de amplias protestas por parte de la alta burguesía (la exportación de capital, una moratoria sobre nuevos inversiones y una disminución en la producción agrícola de exportación). México entró en un período de recesión inflacionaria, y tanto Echeverría como su sucesor el presidente López Portillo respondieron con recortes en el presupuesto del gobierno para el bienestar social. Alimentado por Echeverría durante su «apertura democrática», el clima más tolerante para los MUP dio paso a una política de represión de los movimien-

(10) Agradezco a Paul Haber por compartir sus ideas acerca de cómo los MUP retan las organizaciones de masas del PRI.

(11) Moctezuma («El movimiento urbano popular en México». Nueva antropología 6 , núm. 24,1984 , pp. 61-87) establece la época de reflujo entre 1977 y 1979, mientras que Ramírez Saiz (El movimiento urbano popular en México. México D.F. Siglo XXI, 1986) establece el reflujo entre 1976 y 1978. Entre 1976 y 1979, las instrucciones de la rama ejecutiva del gobierno eran tomar las medidas necesarias para evitar cualquier progreso de los MUP (Meza Ponce, «El movimiento urbano popular de Durango.» Nueva antropología 6, 1984, p. 90). 
tos y la cooptación de sus dirigentes. La erradicación de asentamientos irregulares, el aislamiento de movimientos populares, la represión de los dirigentes de éstos, una especulación incontrolada en los precios de los alquileres, y el asesinato de dos vecinos en una invasión de tierra en la Ciudad de México y seis en Monterrey, caracterizaron esta época. El Regente del Distrito Federal ordenó prevenir las invasiones de tierra, y otros presidentes municipales en el resto del país siguieron sus pasos (12).

En 1977, el presidente López Portillo aprobó una nueva ley que dio como resultado cambios dramáticos en el sistema electoral mexicano y que ofrecía la posibilidad a los partidos de la oposición de participar en las elecciones por primera vez en 1979. Sin embargo, los partidos de la oposición sólo podrían participar en las elecciones bajo las reglas definidas por el partido gobernante, el PRI. Una diferencia clave entre los partidos políticos de la oposición y los MUP era que tras la reforma electoral de 1977, los partidos de la oposición operaban en un ambiente controlado por el partido dominante, mientras que los MUP seguían defendiendo su autonomía. La existencia continuada de los MUP era inaceptable para un régimen que buscaba formas de absorber, manipular, derrocar o controlar a todos sus rivales. A finales de los años 70 , la única respuesta considerada posible por el régimen, era la represión y la cooptación.

Bajo estas condiciones, aunque unas pocas invasiones de tierra tuvieron lugar y se formaron algunos movimientos populares, la mayoría de los MUP trabajaba fundamentalmente para sostener los niveles de organización alcanzados anteriormente. Se establecieron Frentes de Acción Popular en Saltillo, Puebla y Guadalajara, para hacer frente al creciente costo de los servicios urbanos, pero estos frentes se desintegraron con rapidez al disponer de demasiados dirigentes y casi ningún apoyo orgánico (13). En Monterrey hubo una excepción notable, cuando se formó el Frente Popular Tierra y Libertad en 1976. A finales de los 70, los movimientos en Monterrey, Durango y Torreón luchaban contra una disensión interna, resultado de unas diferencias ideológicas basadas en temas como la relación entre el liderazgo y la masa base del movimiento (14). No obstante, hacia principios de 1979, hubo un destacado resurgimiento de la militancia popular.

\section{LA SEGUNDA OLEADA DE MOVIMIENTOS URBANOS POPULARES - 1979 A 1983}

Desde 1979 hasta 1983 hubo un incremento constante en todo México de la formación de colonias populares independientes, de la creación de movimientos urbanos populares, y de la estructuración de coaliciones regionales e incluso nacionales de movimientos urbanos populares. Mientras que el renacimiento de los MUP ocurrió a través de estos cinco años, se puede dividir el período en dos etapas distintas respecto a su contexto económico y político. Los prime-

(12) Ramirez Saiz, op. cit., 1986, pp.59-60.

(13) Ramirez Saiz, op. cit., pp. 54-57.

(14) Ibid, pp. 57-59 ros dos años, 1979 y 1980, corresponden al final del auge del petróleo cuando México recibía abundantes préstamos internacionales y creía con optimismo que sus inmensas reservas de petróleo pagarían el futuro. Los últimos tres años, de 1981 hasta 1983, marcan el principio de la crisis económica de México con devaluaciones repentinas, inflación, recesión, recortes masivos en los presupuestos, despidos y el deterioro acelerado de los niveles de vida para la mayoría de la población.

Desde 1979 hasta 1983 tuvieron lugar nuevas invasiones de tierra y se formaron nuevos movimientos populares en Baja California Norte, Guerrero, Jalisco, el Valle de México, Durango y Sinaloa. Se alcanzaron dos cumbres en este período en 1981, tras la creación a nivel nacional de una federación de movimientos urbanos populares, y tras la creación de un órgano regional coordinador para los MUP en el Valle de México.

En los años 70, el Valle de México, donde vive casi la cuarta parte de la población mexicana, concentró numerosas invasiones de tierra y colonias populares con cierto grado de organización autónoma. Sin embargo, apenas hubo esfuerzos de coordinación entre tales colonias. Hasta 1979, el movimiento urbano popular en el Valle de México era más bien de carácter espontáneo, dirigido a resolver problemas inmediatos de colonias individuales. No obstante, en 1979 y 1980 se crearon dos coaliciones importantes de colonias populares en el Valle de México. La primera, la Unión de Colonias Populares (UCP) (15), fue constituida oficialmente en julio de 1979 con trescientos miembros en siete colonias. Al cumplir su primer aniversario en 1980, la UCP ya comprendía 1.100 miembros en nueve colonias y era uno de los cuatro grupos que coordinaron la primera reunión nacional de movimientos urbanos populares, que se celebró en Monterrey en 1980 (16). La segunda coalición de barrios en el Valle de México fue el Movimiento Popular de Pueblos y Colonias del Sur (MPPCS). Creado en 1980, el MPPCS consistía en ejidos que se habían transformado en colonias urbanas según crecía la Ciudad de México. El MPPCS ha apoyado numerosas huelgas de trabajadores, manifestaciones de campesinos y grupos de liberación centroamericanos (17).

El año 1980 fue decisivo en la evolución de los movimientos urbanos populares en México porque por primera vez los MUP individuales participaron abiertamente en un diálogo a nivel nacional. En mayo de 1980, tuvo lugar en Monterrey el primer congreso nacional de movimientos urbanos populares. El congreso fue organizado por tres de los MUP más importantes de México: la UCP, el FPTyL en Monterrey, el CDP en Durango, junto con el Frente Popular de Zacatecas (FPZ). Un total de quince organizaciones y 700 delegados asistieron al congreso. El motivo del congre-

(15) Toda la información que se presenta en este documento sobre la Unión de Colonias Populares procede de Enzástiga Santiago, Mario. «La Unión de Colonias Populares de cara al movimiento urbano popular: recapitulación histórica.» En Los movimientos sociales en el Valle de México, editado por Jorge Alonso. México D.F.: Centro de Investigaciones y Estudios Superiores en Antropología, Ediciones de la Casa Chata, 1986

(16) La UCP también participó en la comisión organizativa para el Movimiento Revolucionario del Pueblo (MRP) y para la Unidad Obrero Campesino Popular (UOCP).

(17) Arau Chavarria, Rosalinda. "Organización de los pueblos y colonias del sur.» Revista Mexicana de Sociología 19, núm.4, 1987, pp. 9-35. 
so era reunir tanto a los dirigentes como a la base de los MUP, para discutir estrategias, condiciones locales y nacionales e ideología política. Las reuniones concluyeron con un pacto de solidaridad, con la decisión de celebrar un segundo congreso en 1981, y de crear un órgano nacional coordinador que se reuniría cada mes hasta el siguiente congreso nacional (18).

El segundo congreso nacional de los MUP se celebró en Durango en abril de 1981. Esta vez, asistieron 2.000 delegados de sesenta organizaciones de catorce estados. El mayor logro del segundo congreso fue la creación de un órgano coordinador a nivel nacional de los MUP existentes en México: CONAMUP (Coordinadora Nacional del Movimiento Urbano Popular). CONAMUP fue una organización de masas cuyo función consistía en apoyar la evolución de los MUP a través de la República. La CONAMUP organizó las reuniones anuales que permitían el intercambio de información y estrategias; actuó de intermediario entre el gobierno y los MUP locales o regionales; y sintetizó y difundió información sobre el estado actual del movimiento urbano popular en México a través de sus publicaciones.

El plan de acción de la CONAMUP se centró en dos áreas: mejorar las condiciones de vida de la gran mayoría de la población que vivía en condiciones de pobreza y trabajar hacia una sociedad cada vez más democrática, con respeto absoluto para los derechos humanos. La CONAMUP pidió al Estado que dejara de desalojar a inquilinas y a colonos de los asentamientos irregulares, que congelara los alquileres, que proporcionara servicios públicos adecuados, que eliminara el I.V.A. (un impuesto regresivo), que mantuviera los subsidios de precios al consumidor, que dejara en libertad a los presos políticos y que respetara la libertad Democrática del pueblo. La CONAMUP también trabajó para establecer vínculos con las coaliciones que representaban a otros sectores, tales como los campesinos, los trabajadores y los maestros (19).

La CONAMUP no era un partido político, ni se permitía la entrada de los partidos políticos. Uno de los motivos de discordia dentro de la CONAMUP era participar o no en las elecciones. Aquellos que estaban a favor de una participación electoral argumentaban que era una táctica válida que permitiría a los MUP comunicarse con un mayor número de habitantes, mientras que los que estaban en contra de la presentación de candidatos e incluso de votar, argumentaban que las elecciones en México eran una forma utilizada por el gobierno para legitimar su sistema de control hegemónico. Desde su comienzo, los miembros de la CONAMUP acordaron que los MUP individuales mantendrían su autonomía en este asunto, que cada uno decidiría por sí mismo el alcance de su participación electoral y que el CONAMUP, como organización, no participaría (20).

(18) Moctezuma, op. cit., pp. 71-73

(19) La información presentada aquí sobre CONAMUP procede de Ramírez Saiz, op. cit., pp. 172-195.

(20) A mediados hasta finales de los años 80, algunos MUP que habian estado fuertemente en contra de la participación electoral, tomaron la decisión táctica de presentar sus propios candidatos en las elecciones locales. Ejemplos de algunos de esos MUP son el Comité de Defensa Popular de Durango en 1986 y 1988, y el Frente Popular Tierra y Libertad de Monterrey en 1988
Así la Coordinadora Regional del Valle de México (CRMUP) (21), la tercera coalición de movimientos populares en el Valle de México, fue creada en 1981 según los dictámenes de la CONAMUP. La CRMUP se formó para coordinar el MUP en el Valle de México. En 1981 la CRMUP comprendía aproximadamente 25 MUP. Los seis campos que abarcaría serían: a) la posesión legal de tierra, b) los servicios públicos, especialmente el agua, el transporte y la educación, c) la contaminación local, d) impuestos excesivamente altos sobre bienes de propiedad, e) frenar los desahucios masivos y la reubicación forzada de los pobres urbanos que daba lugar al desarrollo urbano más capitalista $y, f)$ el derecho a la existencia de organizaciones populares e independientes, así como el derecho de ejercer una libertad democrática. Mientras la CRMUP trabajaba para organizarse dentro y a través de las delegaciones y distritos del Valle de México, fue incapaz de mantener una miembrecía consistente, porque cada organización participante tenía sus propias necesidades locales como prioridad. El interés de cada organización por participar en las actividades de la CRMUP dependía en un mayor grado de los resultados obtenidos en participaciones anteriores.

En la segunda oleada, según se iban formando nuevos MUP, los movimientos populares que se crearon durante la primera oleada seguían evolucionando. En Durango, se llevaron a cabo nuevas invasiones de tierra con éxito a lo largo de los años 70. En 1979, seiscientos residentes de veinte barrios (no todos fueron invasiones de tierra) crearon una organización que llamaron el Comité de Defensa Popular (CDP-DURANGO) (22). El CDP se creó como una organización popular, sin ningún vínculo con partidos políticos. En 1980, dirigió tres nuevas invasiones de tierra y fue uno de los cuatro movimientos que organizaron el primer congreso nacional de los MUP.

Los años entre 1976 y 1980 fueron un periodo de consolidación para el Frente Popular Tierra y Libertad (creado en 1976) en Monterrey, Nuevo León. Se formaron nuevos poblados de invasión, el Frente apoyó varias huelgas de trabajadores en Monterrey y se estableció un sindicato para los conductores del FPTyL. Sin embargo, empezaron a surgir desacuerdos entre los dirigentes del Frente. Los temas clave incluían el procedimiento en la toma de decisiones, el papel de la base, y los objetivos de la organización respecto a la posible legalización de los terrenos de las colonias invasoras. En 1983, con motivo de la cuestión de la posesión legal de tierra, el FPTyL se dividió en dos grupos: el antiguo FPTyL y el nuevo Movimiento Popular Tierra y Libertad (MPTtL). Dos de los dirigentes originales del Frente, que estaban a favor de la obtención de título legal de la tierra aunque a través del gobierno, abandonaron el Frente para crear el MPTyL. El dirigente restante, que rechazó la

(21) Los datos presentados sobre el CRMUP proceden de Moctezuma, Pedro. «La Coordinadora Nacional del Movimiento Urbano Popular en el Valle de México.» En Alonso, op. cit., 1986.

(22) Muchos otros MUP tienen antecedentes de haber invadido tierra, además de haber pretendido organizar frentes populares. No obstante, el nivel de organización anterior, la continuidad de ello, y el apoyo masivo son más fuertes para el CDP que para cualquier otro MUP que conozco y que se formó después de 1979. El CDP verdaderamente pertenece junto con el FPTyL y el COCEI, como la primera generación de MUP, a pesar del hecho de que se llegó a constituir oficialmente en 1979. 
necesidad de tener título legal de la tierra ya mucho tiempo antes, dispuso del control total del FPTyL. Estas luchas entre los dirigentes, junto con la ruptura y realineación de los colonos en dos facciones, limitó la eficacia del movimiento urbano popular en Monterrey durante gran parte de los años 80 .

En Oaxaca en los 70, el COCEI se dedicó a la movilización de masas, presionando al gobierno para que diera concesiones en numerosos asuntos de los campesinos y obreros. Mientras gran parte de las luchas del COCEI tuvieron éxito, esto no se llevó a cabo sin ningún sacrificio. Hubo una alta represión por parte del gobierno durante estos años: entre 1974 y 1977, más de veinte de los afiliados del COCEI fueron asesinados. En 1980, el COCEI alcanzó un pacto de alianza con el Partido Comunista de México (porque el Partido Comunista era un partido con registro electoral y el COCEI no lo era), permitiendo así que el COCEI presentara candidatos para la administración municipal en Juchitán. Tras cometer un amplio fraude electoral, el PRI se declaró ganador. El COCEI, no obstante, respondió con denuncias furiosas, exigió la anulación de los resultados de las elecciones y ganó unas nuevas elecciones especiales celebradas en 1981. En las nuevas elecciones, los candidatos del COCEI ganaron y desde 1981 hasta 1.983, Juchitán fue la primera ciudad gobernada por una coalición de la izquierda en México (23).

En resumen, los cinco años desde 1979 hasta 1983 constituyen una nueva etapa en la evolución de los movimientos urbanos populares en México. Ya no sólo se hablaba de los problemas cotidianos dentro de las colonias, sino que también se hablaba de ellos a nivel regional y nacional. Los MUP fueron más allá de las colonias para formar coaliciones dentro de las ciudades y a través del país. A pesar de que los primeros dos años de esta etapa coinciden con el último año del auge del petróleo mexicano, y que los últimos tres años coinciden con el comienzo de la crisis económica de México, para los pobres de la ciudad, en esta época, hubo una consistencia notable. La medición macroeconómica de la economía de México da la idea de un auge seguida de una crisis, pero estos desequilibrios en la economía nacional tienen un impacto más limitado sobre los pobres. La falta de vivienda, servicios inadecuados, la especulación en cuanto a los precios de la tierra y los alquileres caracterizaron las ciudades mexicanas en 1968, y también las caracterizaron en 1983. Por tanto, la expansión de los MUP desde 1979 hasta 1983 tanto en tiempos de auge como en tiempos de crisis no es paradójico porque no es una respuesta a los ciclos nacionales económicos, sino una respuesta a la pobreza persistente.

\section{LA TERCERA OLEADA DE MOVIMIENTOS URBANOS POPULARES - 1985 HASTA 1988}

Lo que más destaca de la tercera oleada de los movimientos urbanos populares en México es el hecho de que

(23) En 1981, el candidato del Partido Comunista ganó las elecciones locales para presidente municipal en Alcozauca, un pequeño pueblo con una población de 2.200 personas que se encuentra en el estado de Guerrero casi todos los nuevos MUP surgieron en la capital. El terremoto de 1985 actuó como catalizador para la creación de MUP. Por un lado, decenas de miles de personas se encontraron sin hogar y sin empleo, ya que tanto las casas como los lugares de trabajo resultaron destruidos. Por otro lado, los esfuerzos del gobierno de proporcionar ayuda fueron lentos, insensibles y mal dirigidos. Cuando el gobierno no proporcionó ni liderazgo, ni apoyo moral, ni consejos, la gente se dirigió entre sí. Una nueva fuerza nació a raíz de las actividades inmediatas de buscar entre los escombros y proporcionar alojamiento para los damnificados; una nueva conciencia de lo que se podría conseguir sin usar los medios del gobierno.

Una señal oficial de esto fue la creación de un comité coordinador para representar las necesidades de aquellos que se habían visto afectados por el terremoto. La Coordinadora Unica de Damnificados (CUD) fue constituida por un grupo de veinte colonias un mes después del terremoto. Aunque la primera petición de la CUD fue entregada al Presidente De la Madrid por una masa de 30.000 personas, el gobierno se negó a reconocer a la CUD como el representante de las víctimas del terremoto hasta que el grupo organizó un encierro en la plaza principal de la ciudad. En las reuniones y las asambleas que se celebraron a lo largo del otoño de 1985, la CUD definió los asuntos de máxima prioridad: la vivienda y el empleo (24).

Otro MUP se creó en la Ciudad de México menos de dos años después del terremoto. Inicialmente, también se creó en respuesta a los problemas de vivienda causados por el terremoto. A principios de 1987, dos comités que representaban a inquilinos en la zona central de la Ciudad de México iniciaron una lista con los nombres de familias que aún buscaban alojamiento y que tampoco habían recibido alojamiento en el programa de vivienda del gobierno tras el terremoto. Según se propagaba la voz de que esta lista existía, miles de personas se inscribieron. En abril de 1987, en la Primera Asamblea General de Barrios de la Ciudad de México, la Asamblea de Barrios quedo constituida oficialmente. En diciembre de 1988, 55.000 inquilinos sin alojamiento adecuado se habían apuntado (25).

Después de 1985, se formó un número sin precedentes de movimientos urbanos populares y coaliciones de los MUP (26). Mientras los nuevos MUP que se crearon durante la tercera oleada iban en aumento, los MUP que se habían formado antes de 1985 seguían evolucionando. En Monterrey, el Frente Popular Tierra y Libertad se enfrentó a intentos continuos de cooptación por parte del gobernador del Estado y sufrió las consecuencias de la ruptura del movimiento en 1982. En 1988, el Frente cambió su política de no participar en las elecciones, y su candidato ganó un escaño

(24) Massolo, Alejandra. «QQue el gobierno entienda, lo primero es la vivienda! La Organización de los Damnificados.» Revista Mexicana de Sociología 48, núm. 2, 1986, páginas 195-238.

(25) Véase Hernández S., Ricardo. Asamblea de Barrios. México D.F.: Información Obrera y Equipo Pueblo, 1988; y Tirado Jiménez, Ramón. Asamblea de Barrios: Nuestra Batalla. México D.F.: Editorial Nuestro Tiempo, 1990.

(26) Por ejemplo, la Unión Popular Nuevo Tenochtitlan en 1986, la Unión Popular Revolucionaria Emiliano Zapata en 1987, el Frente Metropolitano en 1987, la Coordinadora de Colonias y Pueblos del Sur, y la Coordinadora de Lucha Urbana, entre otros. 
en el Congreso Nacional. En Oaxaca, a pesar de la severa represión gubernamental en 1983 y 1984, el COCEI mantuvo su base y tras unas elecciones fraudulentas en 1986, consiguió la primera formación de un gobierno de coalición con el PRI en Juchitán, en el cual el COCEI controlaba la mitad de la administración y mantuvo su plataforma para el cambio social. En Durango, el CDP siguió creciendo y fortaleciéndose. También se enfrentó a la represión gubernamental: en 1985 y 1986, dos miembros del CDP fueron asesinados. En 1986, el CDP cambió de posición y decidió participar en las elecciones estatales; lo volvió a hacer en 1988 y como consecuencia ganó un escaño en el Congreso Nacional.

\section{CONCLUSIONES}

A mediados de los 80 , el movimiento urbano popular se había extendido a la mayoría de las ciudades mexicanas. Los movimientos varían en cuanto a su historia, vida, estrategias y la respuesta del gobierno hacia ellos. En algunas ciudades, los MUP sufrían represión, mientras que en otras lograban dialogar con el gobierno. La Ciudad de México presenció el crecimiento de los MUP, mientras que en Durango, el CDP sufría represión y el Frente en Monterrey estaba desgastado e intentaba realinearse. La explicación de esta diversidad se encuentra en la historia de los movimientos individuales, en la evolución de sus relaciones con los gobiernos locales, estatales y federales y en sus contextos regionales.

Una forma de analizar el impacto a largo plazo de los MUP es comparando los dos momentos más destacados en la historia política de la sociedad civil mexicana, 1968 y 1988. En 1988, Cuauhtémoc Cárdenas resultó ser una gran amenaza para el candidato del PRI a la presidencia de México, el primero en varias décadas. El PRI ganó en las urnas, pero reconoció que Cárdenas y su partido, el Frente Democrático Nacional (FDN), habían ganado en la Ciudad de México (27). Las elecciones de 1988 cambiaron y reflejaron un cambio en la política mexicana. El hecho de que muchos entre las clases populares decidieran votar y de que aquellos que votaron decidieran no votar por el PRI contribuyó a la victoria de Cárdenas en la Ciudad de México.

En 1968, los estudiantes y los pobres de las zonas urbanas que estaban pagando el precio del Milagro Mexicano se unieron para llevar a cabo manifestaciones masivas. Las reuniones y las marchas de 1968 fueron una llamada al gobierno para que respondiera a sus exigencias. En 1988, los pobres urbanos, junto con los campesinos, maestros y algunos sectores de la clase obrera, ya habían adquirido casi dos décadas de experiencia en la organización de movimientos

(27) El FDN obtuvo la mayoría de sus votos en las zonas urbanas en los estados del centro, sur y en la costa del golfo, mientras que el PRI ganó en el campo y en algunas ciudades del norte (incluyendo Monterrey y Chihuahua). El PAN obtuvo la mayoria en algunos distritos del Valle de México, y ganó en Mérida, Ciudad Juárez, San Luis de Potosí y León. (Aziz Nassif, Alberto. «Regional Dimensions of Democratization.» En Mexico's Alternative Political Futures, series monográficas, editado por Wayne Cornelius, Judith Gentleman y Peter Smith. La Jolla: Universidad de California, San Diego, Center for U.S.-Mexican Studies, 1989, p.105). autónomos o disidentes. Existían organizaciones formales, independientes del PRI, con sus dirigentes, reglamentos, ideologías, objetivos y estrategias, con distintos grados de éxito, en la mayoría de las ciudades mexicanas. La memoria colectiva de la clase popular ya incluía la organización como una característica normal de la vida urbana. Esto no quiere decir que todos los pobres participaron en los movimientos urbanos populares; más bien quiere decir que la mayoría de ellos aceptaron los MUP como parte de la nueva perspectiva urbana. $\mathrm{O}$ bien participaban ellos mismos, o conocían a alguien que participaba, o bien habían oído hablar de los MUP por boca de otros, de los medios de comunicación, de los partidos políticos y del mismo PRI. Por tanto, entre 1968 y 1988, una diferencia que cabe destacar es que en 1988, los pobres urbanos ya tenían sus propios movimientos. Existían nuevos modos para expresar los problemas cotidianos de la pobreza. Veinte años de organización habían cambiado la sociedad civil en México.

El voto de 1988 fue una exigencia de cambio. La confianza para votar emanó de las dos décadas anteriores de organización y de la genuina alternativa que parece haber representado el FDN. A pesar del hecho de que el FDN era una coalición de partidos que no disponía de una plataforma detallada, el voto sugiere que fuera visto como una visión del futuro en vez de un vínculo con el pasado reciente (28). Las elecciones de 1988 fueron el resultado de la convergencia de dos elementos: el deseo de las clases populares de usar su voto como una estrategia más para exigir cambios, y la aparición de un candidato que simbolizaba un México más justo.

El voto de 1988 tenía tal significado que el gobierno respondió con nuevas estrategias dirigidas a los pobres urbanos. El presidente Salinas ordenó la creación de un nuevo programa gubernamental, el Programa Nacional de Solidaridad (PRONASOL), que se creó para mejorar las condiciones de vida para las capas más bajas de la sociedad. Se desarrolló un nuevo mecanismo por el cual los recursos eran canalizados hacia unos MUP específicos, que firmaron convenios de concertación con el gobierno. Finalmente, el presidente programó estancias nocturnas en las colonias más pobres de la Ciudad de México bien difundidas en la prensa nacional, para mostrar a los ciudadanos que su gobierno no les pasaría por alto (29). El intento de la administración de Salinas de dirigirse a las clases populares ha sido una respuesta a un mayor grado de pobreza urbana, al aumento en la organización popular urbana y al control disminuido del PRI sobre la población urbana. Es un intento de recobrar terreno perdido: la lealtad política de las masas urbanas.

Los cambios ocurridos en México después de 1968, muestran el descubrimiento del barrio como un vehículo

(28) Probablemente también se vio a Cárdenas como un vínculo al pasado lejano: el pasado de su padre, el presidente Lázaro Cárdenas, al que se suele recordar como el presidente mexicano más justo del periodo posrevolucionario. No obstante, Cuautéhmoc Cárdenas representó una alternativa al pasado reciente: la política del PRI de los veinte años abarcados en este documento.

(29) Las nuevas estrategias del gobierno han provocado muchos debates entre los MUP. Algunos niegan su participación, reclamando que los nuevos programas sólo son nuevos métodos de cooptación. Otros han optado por participar, con la convicción de que pueden mantener la autonomía suficiente ante el gobierno para que no suceda la cooptación. 
político por los pobres urbanos y el potencial de ese vehículo para cambios sociales. Fuera de una revolución, el proceso de transformación social suele ser de cambios consecutivos. En México, a principios de los años 70, las clases populares desarrollaron una respuesta autónoma a la pobreza creada por el Milagro Mexicano. Al principio, el gobierno respondió con una apertura democrática. Esto permitió que las organizaciones populares que surgían se fortalecieran. Después, a finales de los 70 , el gobierno respondió con la represión y cooptación de los MUP, y con una apertura política que no aportaba ventajas directas a los MUP. Los MUP sufrieron un reflujo y luego desarrollaron nuevas estrategias incluyendo la formación de redes regionales y na- cionales a principio de los años 80 . Finalmente, después de 1988, el gobierno respondió con nuevos programas que contemplaban las necesidades básicas exigidas por los MUP.

Los programas sociales y las inversiones hechas por la administración de Salinas son reminiscencias de una política populista para acaparar a las clases populares. No obstante, la política de Salinas se realiza en un contexto político bastante diferente, un contexto donde la hegemonía del PRI y la política como siempre están en duda, un ambiente en el que la democratización es el tema principal. Este nuevo ambiente político ha sido parcialmente creado por la organización continua y autónoma de las clases populares mexicanas durante las últimas dos décadas.

\section{RESUMEN}

En este artículo se estudia el devenir de los movimientos populares urbanos en México desde 1968, coincidiendo con un descenso en el apoyo popular al modelo de desarrollo practicado. Su existencia como construcción de nuevos canales de expresión se configura en tres oleadas: los primeros años de la década de 1970, el período 1979-1983, y por último, los años 1985-1988.

\section{ABSTRACT}

In this article, Bennett studies the performance of the Mexican popular urban movements since 1968, and their declinning support to the political development program of the government. Its appearance and existance as a way of construction of new channels of expression is revealed in three waves: the early 1970's, the period 1979-1983, and the last one, the years 1985-1988. 